Marquette University

e-Publications@Marquette

6-28-2019

\title{
Cobalt Superoxo and Alkylperoxo Complexes Derived from Reaction of Ring-Cleaving Dioxygenase Models with $\mathrm{O}_{2}$
}

\author{
Praveen Kumar \\ Marquette University \\ Sergey V. Lindeman \\ Marquette University, sergey.lindeman@marquette.edu \\ Adam T. Fiedler \\ Marquette University, adam.fiedler@marquette.edu
}

Follow this and additional works at: https://epublications.marquette.edu/chem_fac

Part of the Chemistry Commons

\section{Recommended Citation}

Kumar, Praveen; Lindeman, Sergey V.; and Fiedler, Adam T., "Cobalt Superoxo and Alkylperoxo Complexes Derived from Reaction of Ring-Cleaving Dioxygenase Models with $\mathrm{O}_{2}$ " (2019). Chemistry Faculty Research and Publications. 1000.

https://epublications.marquette.edu/chem_fac/1000 
Marquette University

e-Publications@Marquette

\section{Chemistry Faculty Research and Publications/College of Arts and Sciences}

This paper is NOT THE PUBLISHED VERSION; but the author's final, peer-reviewed manuscript. The published version may be accessed by following the link in the citation below.

Journal of the American Chemical Society, Vol. 114, No. 28 (June 28, 2019): 10984-10987. DOI. This article is (C) American Chemical Society and permission has been granted for this version to appear in ePublications@Marquette. American Chemical Society does not grant permission for this article to be further copied/distributed or hosted elsewhere without the express permission from American Chemical Society.

\section{Cobalt Superoxo and Alkylperoxo Complexes Derived from Reaction of Ring-Cleaving Dioxygenase Models with $\mathrm{O}_{2}$}

Praveen Kumar

Department of Chemistry, Marquette University, Milwaukee, Wisconsin Sergey V. Lindeman

Department of Chemistry, Marquette University, Milwaukee, Wisconsin Adam T. Fiedler

Department of Chemistry, Marquette University, Milwaukee, Wisconsin 


\section{Abstract}

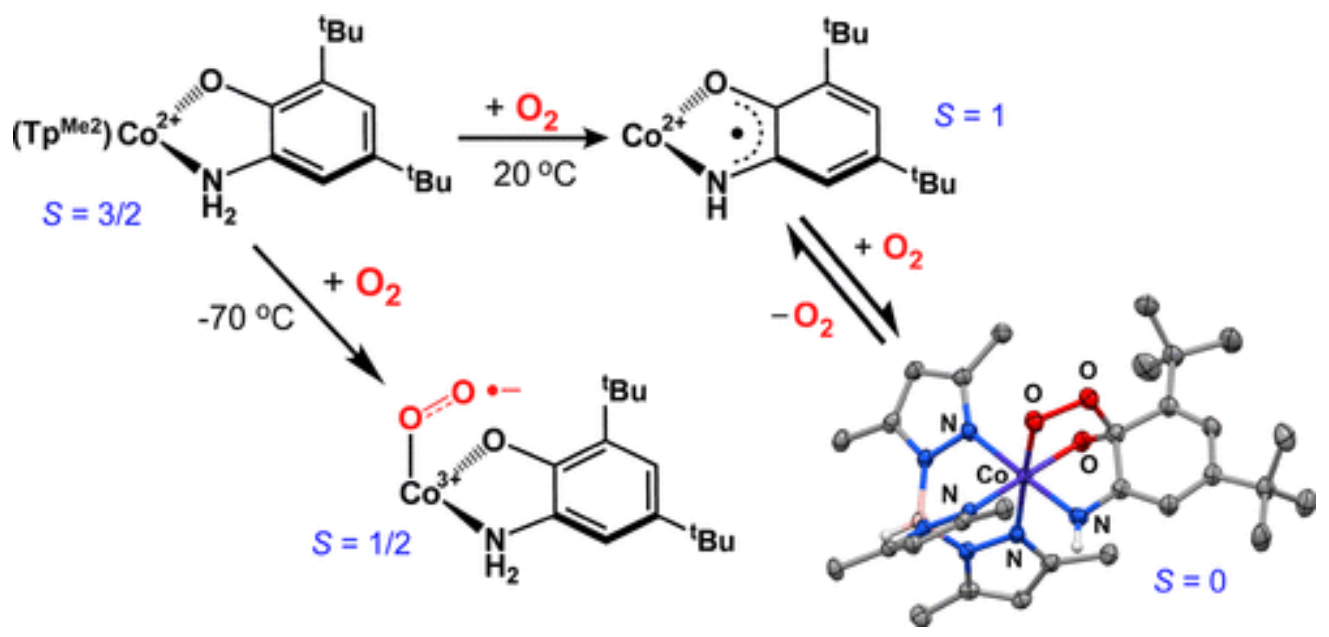

The syntheses and $\mathrm{O}_{2}$ reactivities of active-site models of cobalt-substituted ring-cleaving dioxygenases are presented. The pentacoordinate cobalt(II)-aminophenolate complex, [Co( $\left.\left.\mathrm{Tp}^{\mathrm{Me} 2}\right)\left({ }^{\mathrm{tBu} 2} \mathrm{APH}\right)\right]$, gives rise to two distinct dioxygen adducts at reduced temperatures. The first is a paramagnetic $(S=1 / 2)$ cobalt(III)-superoxo species that was characterized with spectroscopic and computational techniques. The identity of the second $\mathrm{Co} / \mathrm{O}_{2}$ adduct was elucidated by $\mathrm{X}$-ray crystallography, which revealed an unprecedented cobalt(III)-alkylperoxo structure generated by $\mathrm{O}_{2}$ addition to the metal ion and ligand. These results provide synthetic precedents for proposed intermediates in the catalytic cycles of $\mathrm{O}_{2}$-activating cobalt enzymes.

The bacterial breakdown of organic compounds, including human-generated pollutants, often requires dioxygenase enzymes that oxidatively cleave aromatic carbon-carbon bonds using $\mathrm{O}_{2}$.(1) Substrates of these ring-cleaving dioxygenases include substituted catechols, o-aminophenols, 1,4-hydroquinones, and salicylates.(2) The active sites of most ring-cleaving dioxygenases feature a mononuclear nonheme iron center bound facially to one Glu (or Asp) and two His residues.(3) However, recent studies revealed that an extradiol catechol dioxygenase (CatD), homoprotocatechuate-2,3-dioxygenase (HPCD), exhibits equal or greater activity with $\mathrm{Mn}$ or Co in the active site.(4) The "promiscuity" of HPCD supports the mechanistic proposal that $\mathrm{O}_{2}$ activation by ring-cleaving dioxygenases does not necessitate a change in metal oxidation state. Instead, the metal facilitates the transfer of one electron from the coordinated substrate to $\mathrm{O}_{2}$, thereby yielding a $\mathrm{M}(\mathrm{II})$ superoxo species with an (imino)semiquinone radical (B in Scheme 1).(5) Formation of a substrate-based radical encourages attack by the superoxide ligand to generate a putative alkylperoxo species (C), which undergoes rearrangement to insert an $\mathrm{O}$ atom into the substrate ring (D).(6) Analogous mechanisms are likely employed by 0 -aminophenol and 1,4-hydroquinone dioxygenases.(7)

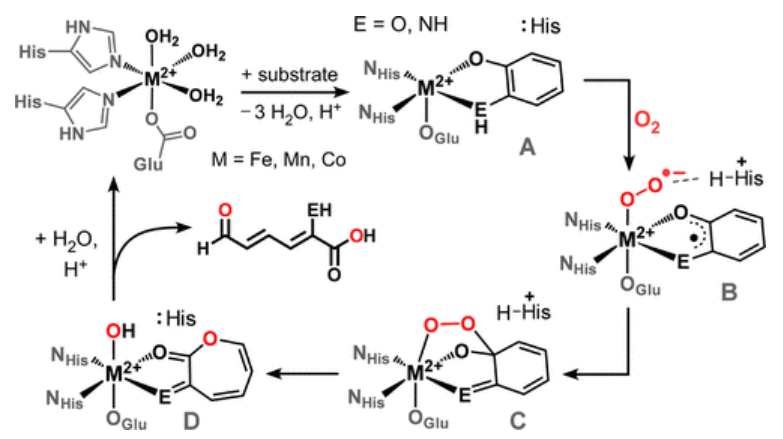

Scheme 1. Proposed Mechanism of Ring-Cleaving Dioxygenases 
The surprising activity of metal-substituted HPCD has stimulated the synthesis of extradiol CatD models featuring $\mathrm{Co}$ and $\mathrm{Mn}$. Yet complexes that replicate the monoanionic, bidentate coordination of the catecholate ligand in the enzyme active site are still lacking. Recently, the Riordan and Hikichi groups reported Co and $\mathrm{Mn}$ complexes, respectively, that feature a monoanionic catecholate ligand bound in a monodentate manner.(8,9) Exposure of these complexes to $\mathrm{O}_{2}$ results in formation of the corresponding $\mathrm{M}(\mathrm{II})$-semiquinonate (SQ) species via loss of an electron and proton (i.e., net $\mathrm{H}$ atom transfer, HAT). Thus, the CatD models fail to replicate the initial $\mathrm{O}_{2}$ binding step of the enzymatic mechanism. In some cases, further reaction of the $\mathrm{Co}(\mathrm{II})-\mathrm{SQ}$ complexes with $\mathrm{O}_{2}$ affords the intradiol ring-cleavage products in low yield.(8)

To avoid the shortcomings of the cobalt-catecholate complexes, we decided to pursue cobalt(II) dioxygenase models that contain an aminophenolate ligand instead. Aminophenol dioxygenases (APDOs) are closely related to extradiol CatDs both structurally and mechanistically,(2) and although a cobalt-substituted APDO has not been generated to date, it is reasonable to expect such an enzyme to display activity. More importantly, we reckoned that the less acidic $-\mathrm{NH}_{2}$ donor would deter formation of a $\mathrm{Co}$ (II)-iminosemiquinone (ISQ) species and provide access to biologically relevant $\mathrm{O}_{2}$ reaction pathways. This hypothesis proved correct, and herein we describe the synthesis of two mononuclear Co(II) complexes (1 and $\mathbf{2}$ in Figure $\mathbf{1}$ ) that feature a monoanionic, bidentate aminophenolate ligand. The 2-histidine-1-carboxylate facial triad of the enzymatic active site is modeled with the $T p^{R 2}$ ligand $\left(R=P h(1)\right.$ or $M e(2) ; T p^{R 2}=$ hydrotris(pyrazolyl-1-yl)borate substituted with $R-$ groups at the 3- and 5-positions). Although HAT reactivity is observed for $\mathbf{1}$ and $\mathbf{2}$ under certain conditions, the latter complex gives rise to $\mathrm{O}_{2}$-derived intermediates not observed for the analogous catecholate complexes, including a cobalt-superoxo species that resembles intermediate B. Furthermore, we report the first X-ray structure of a cobalt-alkylperoxo complex with a structure akin to $\mathbf{C}$ in the proposed ring-cleaving mechanism.

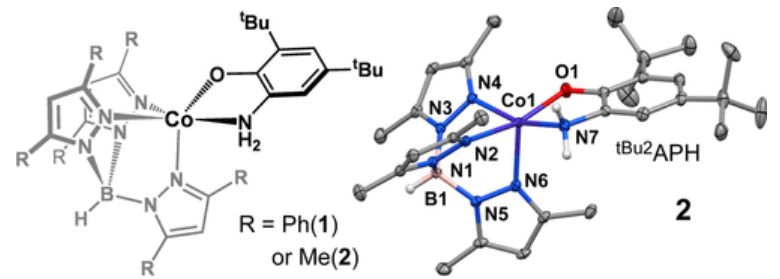

Figure 1. Left: Schematic drawing of [Co(Tp $\left.\left.{ }^{R 2}\right)\left({ }^{\mathrm{Bu} 2} \mathrm{APH}\right)\right](\mathbf{1}$ and 2). Right: X-ray crystal structure of $\mathbf{2}$.

The crystal structures of complexes 1 and $\mathbf{2}$ each revealed a five-coordinate Co(II) center in which the monoanionic ${ }^{\mathrm{B} u 2} \mathrm{APH}$ ligand binds in a bidentate fashion (Figure 1). The $\mathrm{Tp}^{\mathrm{R} 2}$ ligands coordinate facially with average $\mathrm{Co}-\mathrm{N}_{\mathrm{Tp}}$ bond distances of $2.11 \AA$. The $\mathrm{Co}-\mathrm{N} / \mathrm{O}$ bond distances (Table S1) are characteristic of pentacoordinate, high-spin Co(II) complexes. X-band EPR spectra of $\mathbf{1}$ and $\mathbf{2}$ (Figure S3) exhibit features arising from the $m_{s}= \pm 3 / 2$ doublet of the $S=3 / 2$ manifold $(D<0)$. In both spectra, hyperfine splitting from the ${ }^{59} \mathrm{Co}$ nucleus is evident in the low-field resonance near $g \sim 7\left(A_{c_{0}}=85 \mathrm{G}\right.$ for 2$)$.

Complex 1 reacts slowly with $\mathrm{O}_{2}$ to yield a stable, dark green species (10x; Figure $\left.2 \mathrm{a}\right)$. X-ray crystallography determined that $\mathbf{1}^{\text {ox }}$, like its precursor, is a neutral five-coordinate complex. The Co- $\mathrm{N}_{T p}$ bond distances change only slightly from 1 to $\mathbf{1}^{\text {ox }}$ (Table S1), suggesting that the Co center remains divalent and high-spin. Despite these similarities, comparison of the two structures reveals that the ${ }^{\mathrm{tBu}} \mathrm{APH}$ ligand of 1 has been oxidized to an ISQ radical in $\mathbf{1}^{\mathrm{ox}}$. The change is apparent in the shorter $\mathrm{O} 1-\mathrm{C} 1$ and N2-C2 bond distances of $\mathbf{1}^{\mathrm{ox}}$, as well as the quinoidal distortion of its $\mathrm{C}-\mathrm{C}$ bonds (Figure $2 \mathrm{~b}$ ). Using the "metrical oxidation state" method developed by Brown,(10) the ${ }^{\mathrm{tBu}}$ ISQ ligand of $\mathbf{1}^{\mathrm{ox}}$ carries a charge of -0.95 , near the ideal value of -1.0 for an ISQ ligand. The presence of an ${ }^{\mathrm{B}{ }^{\mathrm{B}} 2} \mathrm{ISQ}$ radical is also evident from characteristic $\pi \rightarrow \pi^{*}$ features in the $600-800 \mathrm{~nm}$ region of the absorption spectrum that overlap with Co(II) $d$-d bands (Figure 2a).(11) Complex $\mathbf{1}^{\text {ox }}$ is EPR-silent and the 
observed magnetic moment of $2.9 \mu_{\mathrm{B}}(S=1)$ is indicative of antiferromagnetic coupling between the Co(II) and ${ }^{\mathrm{tB}}{ }^{\mathrm{I}} \mathrm{ISQ}$ spins.
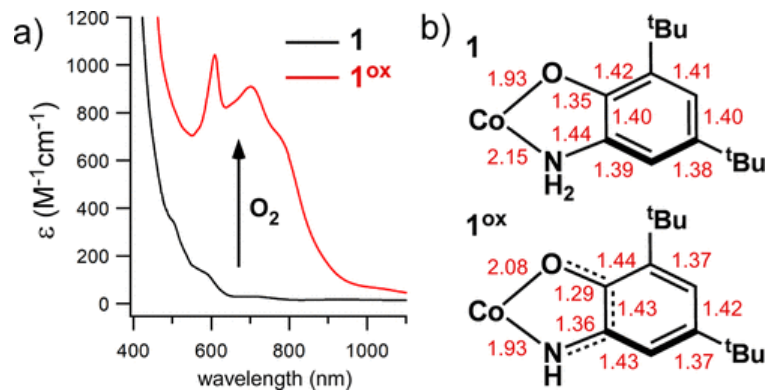

Figure 2. (a) UV-vis absorption spectra of 1 and $1^{\text {ox }}$ in $\mathrm{CH}_{2} \mathrm{Cl}_{2}$ at $20{ }^{\circ} \mathrm{C}$. (b) Selected bond distances $(\AA)$ for the ${ }^{\text {tBu2 }} \mathrm{APH}$ and ${ }^{\mathrm{tB} u}$ ISQ ligands in $\mathrm{X}$-ray structures of $\mathbf{1}$ and $\mathbf{1}^{\text {ox }}$, respectively.

Likewise, exposure of $\mathbf{2}$ to $\mathrm{O}_{2}$ at room temperature (RT) yields a green species $\left(2^{\text {ox }}\right)$ with spectral and magnetic properties similar to $\mathbf{1}^{\text {ox }}$ (Figure S4). A notable difference, however, is that $\mathbf{2}^{\text {ox }}$ decays within minutes at $20^{\circ} \mathrm{C}$, which hindered the growth of suitable crystals. Significantly, $2^{\text {ox }}$ can also be generated under anaerobic conditions by treating 2 with one equivalent of 2,4,6-tri-tert-butylphenoxy radical (TTBP•), a well-known $\mathrm{H}$ atom abstractor (Figure S4). This result demonstrates that the conversion of $\mathbf{2} \rightarrow \mathbf{2}^{\text {ox }}$ involves loss of a proton and electron to generate [Co" $\left.\left(\mathrm{Tp}^{\mathrm{Me} 2}\right)\left({ }^{\mathrm{B} u 2} \mid \mathrm{SQ}\right)\right]$. Nuclear magnetic resonance (NMR) analysis of the reaction mixture after decay of $\mathbf{2}^{\text {ox }}$ in air found that 3,5-di-tert-butyl-o-benzoquinone (DTBQ) is the only product derived from the ${ }^{\mathrm{tBu}} \mathrm{APH}$ ligand (Figure $\mathrm{S} 5$ ). Thus, the overall $\mathrm{O}_{2}$ reaction does not result in oxygenated or ring-cleaved products; instead, the ${ }^{\mathrm{tBu} 2} \mathrm{APH}$ ligand undergoes two-electron oxidation to the corresponding $O$ iminobenzoquinone, followed by hydrolysis to DTBQ upon aqueous workup.

While the $\mathrm{O}_{2}$ reactivity of $\mathbf{1}$ and $\mathbf{2}$ at RT is dominated by HAT chemistry, we found that it is possible to observe

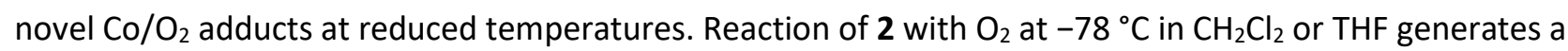
metastable pink species $\left(2-\mathrm{O}_{2}\right)$ with absorption features at $\lambda_{\max }=505$ and $800 \mathrm{~nm}$ (Figure 3a). Purging the solution with Ar does not regenerate $\mathbf{2}$, and warming causes $\mathbf{2}-\mathbf{O}_{\mathbf{2}}$ to convert to $\mathbf{2}^{\mathbf{o x}}$. The X-band EPR spectrum of $2-\mathrm{O}_{2}$ presents a $S=1 / 2$ signal with $g$-values of $2.084,2.007,1.957$ and ${ }^{59} \mathrm{Co}$ hyperfine splitting of $28 \mathrm{G}$ (Figure $3 b$ ). Quantification of the EPR signal indicates that $2-\mathrm{O}_{2}$ accounts for $\sim 80 \%$ of the Co in the sample, with

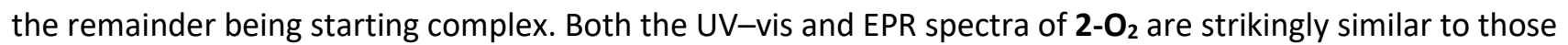
previously reported for $\mathrm{Co} / \mathrm{O}_{2}$ adducts.(12) In particular, the clustering of the $g$-values near 2.0 and the small $A_{c_{0}}$-value of $\mathbf{2}-\mathbf{O}_{2}$ (relative to its $\mathrm{Co}$ (II) precursor) are distinctive characteristics of cobalt(III)-superoxo species, reflecting localization of the unpaired electron on the superoxo ligand. The presence of a superoxo-to-

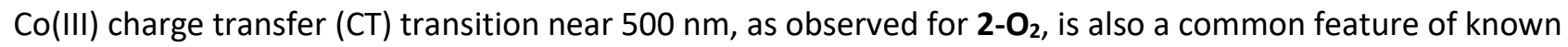
cobalt(III)-superoxo complexes in noncorrinoid environments.(12) Interestingly, complex $\mathbf{1}$ is unreactive with $\mathrm{O}_{2}$ at low temperatures, suggesting that sterics modulate the energetics of $\mathrm{O}_{2}$ binding.

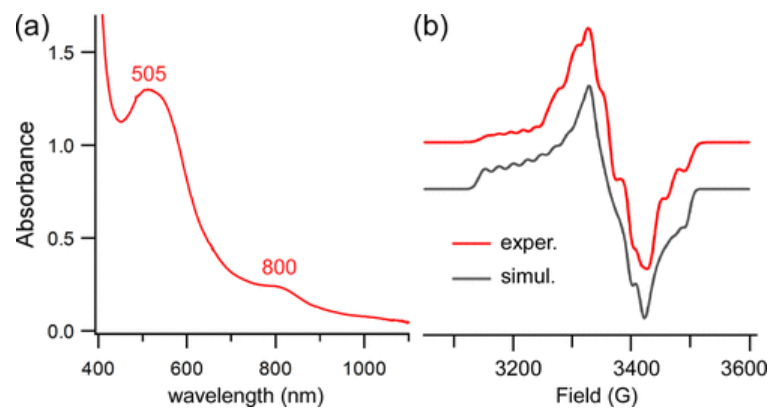

Figure 3. (a) UV-vis absorption spectrum of $2-\mathrm{O}_{2}$ obtained by reaction of 2 with $\mathrm{O}_{2}$ in THF at $-70^{\circ} \mathrm{C}$. [2] initial $=1.25 \mathrm{mM}$. (b) Xband EPR spectrum (red) of $\mathbf{2 - \mathbf { O } _ { 2 }}$ in frozen THF at $\mathbf{7 7} \mathrm{K}$. Parameters for the simulated spectrum (gray) are provided in the SI. 
The geometric and electronic structures of $\mathbf{2}-\mathbf{O}_{2}$ were further analyzed using density functional theory (DFT) calculations. The geometry-optimized structure (Figure S6) features an end-on superoxo ligand in a bent conformation. The superoxo nature of the $\mathrm{O}_{2}$ ligand is reflected in the computed $\mathrm{O}-\mathrm{O}$ distance of $1.278 \AA$. The six-coordinate $\mathrm{Co}(\mathrm{III})$ center is low-spin and nearly all of the unpaired spin density resides on the superoxo ligand, consistent with the EPR data. The computed ${ }^{59} \mathrm{Co}$ A-tensor is anisotropic with a dominant hyperfine splitting of $26 \mathrm{G}$, in excellent agreement with the experimental value. The $g$-values predicted by CASSCF/NEVPT2 calculations $\left(g_{1,2,3}=2.060,1.991\right.$ and 1.979$)$ reproduce the weak anisotropy of the $\mathbf{2}-\mathbf{O}_{2}$ signal. Thus, the computational data further corroborate the assignment of $\mathbf{2 - \mathbf { O } _ { 2 }}$ as a cobalt(III)-superoxo species.

Interestingly, we found that a second $\mathrm{Co} / \mathrm{O}_{2}$ adduct with spectroscopic features distinct from $\mathbf{2}-\mathbf{O}_{\mathbf{2}}$ is generated when $\mathbf{2}^{\mathbf{o x}}$ is treated with $\mathrm{O}_{2}$ at reduced temperatures. Aerobic solutions of $\mathbf{2}^{\mathbf{o x}}$ in $\mathrm{CH}_{3} \mathrm{CN}$ and $\mathrm{CH}_{2} \mathrm{Cl}_{2}$ change from dark green to light brown upon cooling. Monitoring the process by UV-vis spectroscopy revealed that the species generated at low temperature (3) lacks well-defined absorption features in the visible region (Figure 4a). The absorption features of $\mathbf{2}^{\mathbf{o x}}$ return when the solution is warmed to RT, but full intensity is not recovered due to its instability. No color change is observed during cooling if $\mathbf{2}^{\mathbf{0 x}}$ is generated anaerobically via reaction with

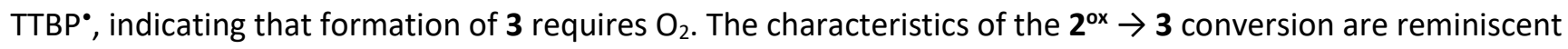
of those previously reported for the $\mathrm{O}_{2}$ reaction of cobalt(II)-semiquinonate complexes at reduced temperatures.(8b,9b) Because of this, we prepared and structurally characterized [Co"l( $\left(\mathrm{Tp}^{\mathrm{Me} 2}\right)\left({ }^{\mathrm{tBu} 2} \mathrm{SQ}\right)$ ] (4; Figure S7), the SQ analogue of $2^{\circ x}$. Complex 4 reacts with $\mathrm{O}_{2}$ at $T<-40{ }^{\circ} \mathrm{C}$ to give a brown chromophore (5) with absorption features similar to those of $\mathbf{3}$ (Figure S8). Like $\mathbf{3}$, species $\mathbf{5}$ is EPR-silent and variable-temperature NMR experiments indicate that both $\mathrm{Co} / \mathrm{O}_{2}$ adducts are diamagnetic (Figures S9-S11).

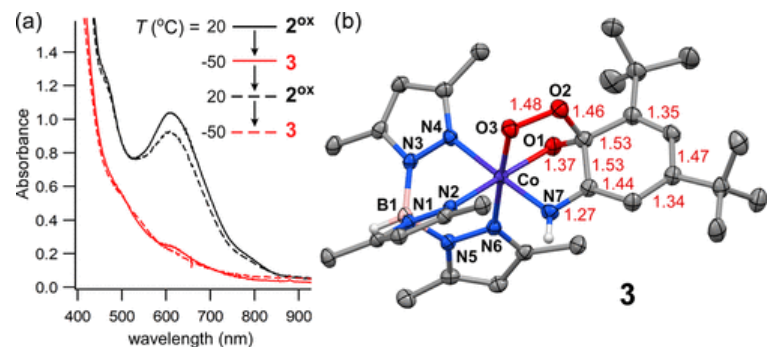

Figure 4. (a) UV-vis spectral changes for the thermal interconversion of $\mathbf{2}^{\mathbf{0 x}}$ (black) and $\mathbf{3}$ (red) in $\mathrm{CH}_{2} \mathrm{Cl}_{2}$ in the presence of $\mathrm{O}_{2}$. $[\mathrm{Co}]=0.7 \mathrm{mM}$ (b) Ellipsoid plot derived from the X-ray structure of 3. Selected bond lengths (Å) are provided in red.

Due to its stability at temperatures below $-25^{\circ} \mathrm{C}$, we succeeded in growing light brown crystals of $\mathbf{3}$ for $\mathrm{X}$-ray analysis. The resulting crystal structure revealed a neutral cobalt-alkylperoxo complex in which the $\mathrm{O}_{2}$-derived atoms form a bridge between $\mathrm{Co}$ and $\mathrm{C} 1$ of the ligand (Figure 4b), thereby generating a five-membered metallocycle. The 02-03 distance of 1.482(3) A is typical of alkylperoxo ligands, and the $s p^{3}$ hybridization of the $\mathrm{C} 1$-atom is evident from its average bond angle of $110^{\circ} \pm 7^{\circ}$. The $\mathrm{Co}-\mathrm{N} / \mathrm{O}$ bond distances in 3 are shorter than those of 2 by an average of $0.15 \AA$, indicating a change from high-spin Co(II) to low-spin Co(III). Comparison of $\mathbf{3}$ to $\mathbf{1}^{\text {ox }}$ reveals that the quinoidal distortion of the ligand is far more pronounced in the former complex, and the metric parameters observed for $\mathbf{3}$ are characteristic of iminobenzoquinone ligands.(10) Thus, formation of $\mathbf{3}$ is a two-electron process involving oxidation of both the Co center and ${ }^{\mathrm{H} B}{ }^{\mathrm{I}}$ ISQ ligand (Scheme 2). 


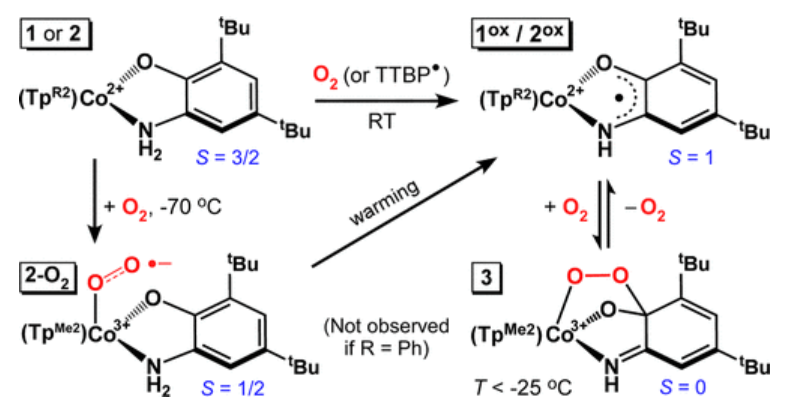

Scheme 2. Species Generated by Reaction of Complexes 1 and $\mathbf{2}$ with $\mathrm{O}_{2}$

The "spiroendoperoxide" structure of $\mathbf{3}$ is the first of its kind among first-row transition metal complexes; indeed, it represents the only X-ray structure to date of a synthetic dioxygen adduct with direct relevance to ring-cleaving dioxygenases. The closest analogues are $\mathrm{Rh}$ (III)- and $\mathrm{Ir}(\mathrm{III})$-alkylperoxo complexes generated by $\mathrm{O}_{2}$ addition to a 9,10-phenanthrene-catecholate(2-) ligand.(13) Similarly, Gade recently reported a square-planar nickel(II) complex that features an alkylperoxometallocycle derived from $\mathrm{O}_{2 .}$ (14) In main-group chemistry, Abakumov showed that a series of $\mathrm{Sb}(\mathrm{V})$-amidophenolate complexes reversibly bind $\mathrm{O}_{2}$ to yield an alkylperoxo donor.(15) As for biological precedents, the structure 3 closely resembles the iron-alkylperoxo intermediate observed by Lipscomb in a crystal structure of HPCD.(16)

As summarized in Scheme 2, we have explored the $\mathrm{O}_{2}$ reaction landscape of two cobalt(II)-aminophenolate complexes. These studies led to the isolation and characterization of cobalt(III)-superoxo $\left(\mathbf{2}-\mathbf{O}_{2}\right)$ and -alkylperoxo (3) species that mimic proposed intermediates of ring-cleaving dioxygenases. It is instructive that subtle differences between these synthetic $\mathrm{Co} / \mathrm{O}_{2}$ adducts and their enzymatic counterparts account for the lack of ring-cleavage activity exhibited by our synthetic models. Specifically, the low-spin Co(III) center of $\mathbf{3}$ stabilizes the alkylperoxo ligand and prevents subsequent $\mathrm{O}-\mathrm{O}$ bond cleavage, whereas the high-spin $\mathrm{Co}(\mathrm{II})$ ion in the putative enzymatic intermediate facilitates insertion of the distal $\mathrm{O}$ atom into the ring via Criegee rearrangement. In our models, the inability of $\mathbf{2}-\mathbf{O}_{2}$ to convert to the requisite cobalt(II)-alkylperoxo intermediate is likely due to the lack of unpaired spin density within the $\left[\mathrm{Co}^{3+}{ }_{-}{ }^{\mathrm{Bu}}{ }^{\mathrm{A}} \mathrm{APH}\right]$ unit, which hinders $\mathrm{O}-\mathrm{C}$ bond formation. The enzyme avoids this scenario by coupling $\mathrm{O}_{2}$ binding to a proton transfer from the substrate to a conserved second-sphere His residue. According to computational studies, this process yields a superoxoCo(II)-substrate radical species (B in Scheme 1) that is primed for alkylperoxo formation.(17) Future efforts in our laboratory will be directed toward the design of functional active-site mimics that replicate the ability of the enzyme to control both $\mathrm{H}^{+}$transfer and $\mathrm{O}_{2}$ binding.

\section{Supporting Information}

The Supporting Information is available free of charge on the ACS Publications website at DOI: $10.1021 /$ jacs.9b05320.

Experimental procedures, computational methods and models, spectroscopic data (EPR, ${ }^{1} \mathrm{H}$ NMR, UV-vis) (PDF)

Crystallographic information (CIF)

pdf

ja9b05320_si_001.pdf (3.9 MB)

crystallographic information file

ja9b05320_si_002.cif (5.58 MB) 
The authors declare no competing financial interest.

Terms \& Conditions

Electronic Supporting Information files are available without a subscription to ACS Web Editions. The American Chemical Society holds a copyright ownership interest in any copyrightable Supporting Information. Files available from the ACS website may be downloaded for personal use only. Users are not otherwise permitted to reproduce, republish, redistribute, or sell any Supporting Information from the ACS website, either in whole or in part, in either machine-readable form or any other form without permission from the American Chemical Society. For permission to reproduce, republish and redistribute this material, requesters must process their own requests via the RightsLink permission system. Information about how to use the RightsLink permission system can be found at http://pubs.acs.org/page/copyright/permissions.html.

\section{Acknowledgments}

This research received financial support from the National Institutes of Health (GM126522). Improvements to the X-band EPR instrument at Marquette University were funded through a grant from the National Science Foundation (CHE-1532168). We thank Dr. Sheng Cai for assistance with the variable-temperature NMR experiments.

\section{References}

1 Wang, Y.; Li, J.; Liu, A. Oxygen activation by mononuclear nonheme iron dioxygenases involved in the degradation of aromatics. JBIC, J. Biol. Inorg. Chem. 2017, 22, 395-405, DOI: 10.1007/s00775-017-14365

2 Vaillancourt, F. H.; Bolin, J. T.; Eltis, L. D. The ins and outs of ring-cleaving dioxygenases. Crit. Rev. Biochem. Mol. Biol. 2006, 41, 241- 267, DOI: 10.1080/10409230600817422

3 (a) Koehntop, K. D.; Emerson, J. P.; Que, L. The 2-His-1-carboxylate facial triad: a versatile platform for dioxygen activation by mononuclear non-heme iron(II) enzymes. JBIC, J. Biol. Inorg.

Chem. 2005, 10, 87-93, DOI: 10.1007/s00775-005-0624-x. (b) Bruijnincx, P. C. A.; van Koten, G.; Klein Gebbink, R. J. M. Mononuclear non-heme iron enzymes with the 2-His-1-carboxylate facial triad: recent developments in enzymology and modeling studies. Chem. Soc. Rev. 2008, 37, 2716-2744, DOI: 10.1039/b707179p

4 (a) Emerson, J. P.; Kovaleva, E. G.; Farquhar, E. R.; Lipscomb, J. D.; Que, L. Swapping metals in Fe- and Mndependent dioxygenases: Evidence for oxygen activation without a change in metal redox state. Proc. Natl. Acad. Sci. U. S. A. 2008, 105, 7347-7352, DOI: 10.1073/pnas.0711179105. (b) Fielding, A.

J.; Kovaleva, E. G.; Farquhar, E. R.; Lipscomb, J. D.; Que, L., Jr. A hyperactive cobalt-substituted extradiolcleaving catechol dioxygenase. JBIC, J. Biol. Inorg. Chem. 2011, 16, 341- 355, DOI: 10.1007/s00775-0100732-0. (c) Fielding, A. J.; Lipscomb, J. D.; Que, L. Characterization of an $\mathrm{O}_{2}$ adduct of an active cobaltsubstituted extradiol-cleaving catechol dioxygenase. J. Am. Chem. Soc. 2012, 134, 796- 799, DOI: 10.1021/ja2095365. (d) Fiedler, A. T.; Fischer, A. A. Oxygen activation by mononuclear Mn, Co, and Ni centers in biology and synthetic complexes. JBIC, J. Biol. Inorg. Chem. 2017, 22, 407-424, DOI: 10.1007/s00775-016-1402-7

5 Fielding, A. J.; Lipscomb, J. D.; Que, L., Jr. A two-electron-shell game: intermediates of the extradiol-cleaving catechol dioxygenases. JBIC, J. Biol. Inorg. Chem. 2014, 19, 491- 504, DOI: 10.1007/s00775-014-1122-9

6 (a) Lipscomb, J. D. Mechanism of extradiol aromatic ring-cleaving dioxygenases. Curr. Opin. Struct. Biol. 2008, 18, 644-649, DOI: 10.1016/j.sbi.2008.11.001. (b) Kovaleva, E. G.; Lipscomb, J. D. Versatility of biological non-heme Fe(II) centers in oxygen activation reactions. Nat. Chem. Biol. 2008, 4, 186- 193, DOI: 10.1038/nchembio.71

7 (a) Dong, G.; Lu, J.; Lai, W. Insights into the Mechanism of Aromatic Ring Cleavage of Noncatecholic Compound 2-Aminophenol by Aminophenol Dioxygenase: A Quantum Mechanics/Molecular Mechanics Study. ACS 
Catal. 2016, 6, 3796- 3803, DOI: 10.1021/acscatal.6b00372. (b) Machonkin, T. E.; Doerner, A. E. Substrate Specificity of Sphingobium chlorophenolicum 2,6-Dichlorohydroquinone 1,2Dioxygenase. Biochemistry 2011, 50, 8899-8913, DOI: 10.1021/bi200855m

8 (a) Wang, P.; Yap, G. P. A.; Riordan, C. G. Five-coordinate $\mathrm{M}^{\prime \prime}$-semiquinonate ( $\mathrm{M}=\mathrm{Fe}, \mathrm{Mn}, \mathrm{Co}$ ) complexes: reactivity models of the catechol dioxygenases. Chem. Commun. 2014, 50, 5871-5873, DOI: 10.1039/C3CC49143A. (b) Wang, P.; Yap, G. P. A.; Riordan, C. G. Synthesis, characterization and $\mathrm{O}_{2}$ reactivity of a bioinspired cobalt(II)-catecholate complex. Inorg. Chim. Acta 2019, 488, 49- 55, DOI: 10.1016/j.ica.2019.01.007

9 (a) Agake, S.-i.; Komatsuzaki, H.; Satoh, M.; Agou, T.; Tanaka, Y.; Akita, M.; Nakazawa, J.; Hikichi, S. A monomeric manganese(II) catecholato complex: Synthesis, crystal structure, and reactivity toward molecular oxygen. Inorg. Chim. Acta 2019, 484, 424-429, DOI: 10.1016/j.ica.2018.09.013. (b) Ikeda, A.; Hoshino, K.; Komatsuzaki, H.; Satoh, M.; Nakazawa, J.; Hikichi, S. $\mathrm{O}_{2}$ activation and external substrate oxidation capability of a Co(II)-semiquinonato complex. New J. Chem. 2013, 37, 2377-2383, DOI: 10.1039/c3nj00215b

10 Brown, S. N. Metrical Oxidation States of 2-Amidophenoxide and Catecholate Ligands: Structural Signatures of Metal-Ligand pi Bonding in Potentially Noninnocent Ligands. Inorg. Chem. 2012, 51, 1251-1260, DOI: 10.1021/ic202764j

11 Bittner, M. M.; Kraus, D.; Lindeman, S. V.; Popescu, C. V.; Fiedler, A. T. Synthetic, Spectroscopic, and DFT Studies of Iron Complexes with Iminobenzo(semi)quinone Ligands: Implications for o-Aminophenol Dioxygenases. Chem. - Eur. J. 2013, 19, 9686- 9698, DOI: 10.1002/chem.201300520

12 (a) Wang, C.-C.; Chang, H.-C.; Lai, Y.-C.; Fang, H.; Li, C.-C.; Hsu, H.-K.; Li, Z.-Y.; Lin, T.-S.; Kuo, T.-S.; Neese, F.; Ye, S.; Chiang, Y.-W.; Tsai, M.-L.; Liaw, W.-F.; Lee, W.-Z. A Structurally Characterized Nonheme CobaltHydroperoxo Complex Derived from Its Superoxo Intermediate via Hydrogen Atom Abstraction. J. Am. Chem. Soc. 2016, 138, 14186-14189, DOI: 10.1021/jacs.6b08642. (b) Oddon, F.; Chiba, Y.; Nakazawa, J.; Ohta, T.; Ogura, T.; Hikichi, S. Characterization of Mononuclear Non-heme Iron(III)-Superoxo Complex with a Five-Azole Ligand Set. Angew. Chem., Int. Ed. 2015, 54, 7336- 7339, DOI: 10.1002/anie.20150236. (c) Corona, T.; Padamati, S. K.; Acuna-Pares, F.; Duboc, C.; Browne, W. R.; Company, A. Trapping of superoxido cobalt and peroxido dicobalt species formed reversibly from $\mathrm{Co}^{\prime \prime}$ and $\mathrm{O}_{2}$. Chem. Commun. 2017, 53, 11782- 11785, DOI: 10.1039/C7CC05904C. (d) Gordon, J. B.; Vilbert, A. C.; Siegler, M. A.; Lancaster, K. M.; Moenne-Loccoz, P.; Goldberg, D. P. A Nonheme Thiolate-Ligated Cobalt Superoxo Complex: Synthesis and Spectroscopic Characterization, Computational Studies, and Hydrogen Atom Abstraction Reactivity. J. Am. Chem. Soc. 2019, 141, 3641-3653, DOI: 10.1021/jacs.8b13134. (e) Fischer, A. A.; Lindeman, S. V.; Fiedler, A. T. Spectroscopic and computational studies of reversible $\mathrm{O}_{2}$ binding by a cobalt complex of relevance to cysteine dioxygenase. Dalton

Trans 2017, 46, 13229- 13241, DOI: 10.1039/C7DT01600J. (f) Jones, R. D.; Summerville, D. A.; Basolo, F. Synthetic oxygen carriers related to biological systems. Chem. Rev. 1979, 79, 139- 79, DOI: 10.1021/cr60318a002

13 (a) Barbaro, P.; Bianchini, C.; Mealli, C.; Meli, A. Synthetic models for catechol 1,2-dioxygenases. Interception of a metal catecholate-dioxygen adduct. J. Am. Chem. Soc. 1991, 113, 3181-3, DOI:

10.1021/ja00008a062. (b) Dutta, S.; Peng, S.-M.; Bhattacharya, S. Ligand Control on Molecular Oxygen Activation by Rhodium Quinone Complexes. Inorg. Chem. 2000, 39, 2231-2234, DOI: 10.1021/ic990999v

14 Rettenmeier, C. A.; Wadepohl, H.; Gade, L. H. Structural Characterization of a Hydroperoxo Nickel Complex and Its Autoxidation: Mechanism of Interconversion between Peroxo, Superoxo, and Hydroperoxo Species. Angew. Chem., Int. Ed. 2015, 54, 4880- 4884, DOI: 10.1002/anie.201500141

15 Abakumov, G. A.; Poddel'sky, A. I.; Grunova, E. V.; Cherkasov, V. K.; Fukin, G. K.; Kurskii, Y. A.; Abakumova, L. G. Reversible binding of dioxygen by a non-transition-metal complex. Angew. Chem., Int. Ed. 2005, 44, 2767-2771, DOI: 10.1002/anie.200462503

16 Kovaleva, E. G.; Lipscomb, J. D. Crystal structures of $\mathrm{Fe}^{2+}$ dioxygenase superoxo, alkylperoxo, and bound product intermediates. Science 2007, 316, 453-457, DOI: 10.1126/science.1134697 
17 Cao, L.; Dong, G.; Lai, W. Reaction Mechanism of Cobalt-Substituted Homoprotocatechuate 2,3-Dioxygenase: A QM/MM Study. J. Phys. Chem. B 2015, 119, 4608- 4616, DOI: 10.1021/acs.jpcb.5b00613 